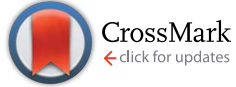

Cite this: J. Mater. Chem. A, 2016, 4, 17121

Received 22nd June 2016

Accepted 4th October 2016

DOI: $10.1039 / c 6 t a 05262 b$

www.rsc.org/MaterialsA

\section{Effect of coatings on the green electrode processing and cycling behaviour of $\mathrm{LiCOPO}_{4} \dagger$}

\author{
Nina Laszczynski, abc Agnese Birrozzi, ${ }^{\text {ab }}$ Krzysztof Maranski, ${ }^{d}$ Mark Copley, ${ }^{d}$ \\ Manfred Erwin Schuster ${ }^{d}$ and Stefano Passerini ${ }^{\star a b}$
}

\begin{abstract}
Several approaches involving carbon and $\mathrm{VO}_{x}$ coatings of $\mathrm{LiCoPO}_{4}$ to enable aqueous electrode processing are reported in this manuscript along with detailed physico-chemical and electrochemical investigations. It is shown that the choice of the carbon source has a severe impact not only on the purity, particle size and morphology of $\mathrm{LiCOPO}_{4}$, but also on its electrochemical performance. Although carbon coating improves the conductivity of $\mathrm{LiCOPO}_{4}$ and protects the particles' surface from direct contact with the electrolyte, it also leads to capacity fading upon cycling at high potentials. Reducing the carbon amount leads to an initially reduced capacity, but it significantly improves the stability upon cycling. Finally, the application of an additional $\mathrm{VO}_{x}$ coating was also investigated.
\end{abstract}

\section{Introduction}

Nowadays, "4 V" cathode materials, e.g., $\mathrm{LiFePO}_{4}, \mathrm{LiMn}_{2} \mathrm{O}_{4}$, $\mathrm{LiCoO}_{2}$ or $\mathrm{LiNi}_{1 / 3} \mathrm{Co}_{1 / 3} \mathrm{Mn}_{1 / 3} \mathrm{O}_{2}$, are used in commercial Li-ion batteries for small electronic devices as well as hybrid (HEV) and full (FEV) electric vehicles. ${ }^{1-3}$ However, higher cell potentials are required in order to achieve the energy and power densities needed, especially, for electric vehicles. Toward such a target, the family of olivines is in the focus of research. In particular, $\mathrm{LiNiPO}_{4}$ (LNP) and $\mathrm{LiCoPO}_{4}$ (LCP), offering working potentials above $5 \mathrm{~V}$ and around $4.8 \mathrm{~V}$, respectively, and theoretical specific capacities above $165 \mathrm{~mA} \mathrm{~h} \mathrm{~g}{ }^{-1}$, are under consideration. Besides the theoretical energy performance, olivines show the advantage of superior safety among other cathode materials due to the covalent $\mathrm{P}-\mathrm{O}$ bonds of the highly stable $\mathrm{PO}_{4}$ units. These bonds do not result in oxygen release upon heating, thus sharply reducing the risk of cell thermal runaway. ${ }^{4,5}$ However, olivines suffer from low electronic conductivity which is well known for $\mathrm{LiFePO}_{4}$ (LFP); thus this issue has been deeply investigated and solved for LFP. Decreasing the particle size to the nanoscale, i.e., reducing the length of the electronic paths, and applying a carbon coating increase the overall electronic conductivity in and among LFP particles. ${ }^{6}$ The same approach is, in theory, suitable for LCP and

${ }^{a}$ Helmholtz Institute Ulm (HIU), Helmholtzstr. 11, 89081, Ulm, Germany ${ }^{b}$ Karlsruhe Institute of Technology (KIT), P. O. Box 3640, 76021 Karlsruhe, Germany. E-mail: stefano.passerini@kit.edu

'Institute of Physical Chemistry, University of Muenster, Corrensstr. 28/30, 48149 Muenster, Germany

dJohnson Matthey Technology Centre, Blount's Court Road, Sonning Common, Reading, RG4 9NH, UK

$\dagger$ Electronic supplementary information (ESI) available. See DOI: $10.1039 /$ c6ta05262b
LNP as well. However, concerns exist about the stability of carbon at elevated potentials. In fact, conductive carbons (i.e., the carbon added into composite electrodes to enhance their overall electronic conductivity) were reported to suffer from oxidation and reaction with the electrolyte. ${ }^{7}$

Aside from the active material choice, electrode processing is an important factor for the production of Li-ion batteries for commercial devices where cost and environmental impact are among the main requirements. Aqueous processing not only is environmentally benign because no volatile organic solvents need to be used, but is also more cost efficient since the binder itself is cheaper than polyvinylidene fluoride (PVdF), the most commonly used binder for LIB cathodes and, moreover, the costly recovery of (toxic) $N$-methyl-pyrrolidone (NMP) can be avoided. ${ }^{8-10}$ Since sodium carboxymethylcellulose (CMC) has been proven as an effective binder for carbon coated LFP, it has been investigated herein for LCP electrodes. ${ }^{\mathbf{1 1 - 1 3}}$

Within this work the application of carbon coatings from different precursors as well as of an additional $\mathrm{VO}_{x}$ coating onto LCP nanoparticles is investigated with respect to the aqueous processing of such materials into electrodes. Three different carbon sources were used, namely, sucrose, polyacrylic acid (PAA) and polyoxyethylene (20)-sorbitan-monooleate (Tween $80 \AA)$. While the first material shows a relatively low decomposition temperature (easy to carbonize), the second shows a chelating behavior and is known to protect metals from corrosion. $^{\mathbf{1 4 , 1 5}}$ The third precursor is a derivative of oleic acid, bearing a ring structure that was shown to improve the cycling stability of LFP. ${ }^{16}$ Following a different approach, the application of an additional vanadium oxide coating, starting from the crystalline layer of $\mathrm{V}_{2} \mathrm{O}_{5}$ as a precursor, was investigated. The coating is referred as $\mathrm{VO}_{x}$ to indicate that the nature of the material might have been partially changed from the starting 
$\mathrm{V}_{2} \mathrm{O}_{5}$. In fact, it was impossible to determine exactly the oxidation state and the structure of the vanadium phase since the coated sample appeared to be susceptible to the TEM electron beam, thus complicating data interpretation. Although $\mathrm{VO}_{x}$ is not a good electronic conductor, a very thin layer of $\mathrm{VO}_{x}$ on the particle surface of $\mathrm{Li}_{2} \mathrm{MnO}_{3} \cdot \mathrm{LiMO}_{2}(\mathrm{M}=\mathrm{Ni}, \mathrm{Mn}$, Co), also operating above $4.5 \mathrm{~V}$, was shown to significantly enhance the capacity and cycling performance. ${ }^{\mathbf{1 7}}$

As shown later in this manuscript, the carbon coating enhances significantly the conductivity of LCP electrodes which, therefore, deliver higher capacities. However, such electrodes still suffer from significant fading upon cycling, thus offering poor capacity retention. The $\mathrm{VO}_{x}$ coating, instead, reduces overall the active materials' specific capacity.

\section{Experimental}

\section{Synthesis and coating of $\mathrm{LiCoPO}_{4}$}

A precursor of LCP was synthesized at the Johnson Matthey Technology Centre by flame spray pyrolysis. In summary, the synthesis involves the preparation of a precursor solution containing Li, Co and $\mathrm{P}$ species dissolved in organic solvents. Igniting the sprayed solution (in an aerobic environment) results in the formation of nanoparticles, which were collected for further processing. Prior to calcination different coating precursors were applied on the LCP precursor, namely, those based on carbon and vanadium.

For the carbon coating, sucrose (LCP/C1 and LCP/C2) and polyacrylic acid (LCP/C3) were dissolved in ultrapure water (MilliQ). To these solutions, an appropriate amount of LCP precursor was added in order to obtain sucrose : LCP weight ratios of 0.2 and 0.1 and a PAA : LCP weight ratio of 0.2 . The resulting slurries were mixed for $2 \mathrm{~h}$ at $400 \mathrm{rpm}$ using a planetary ball mill (Vario-Planetary Mill Pulverisette 4, Fritsch).${ }^{14}$ The slurries were dried at $60{ }^{\circ} \mathrm{C}$ for $12 \mathrm{~h}$ and ground afterwards. When using polyoxyethylene (20)-sorbitan-monooleate (Tween $80 \AA$, Merck Millipore) as the carbon source (LCP/C4), the precursor of LCP was added to an aqueous solution of Tween $80 \AA$ (weight ratio 0.4 ) and the resulting slurry was mixed for $8 \mathrm{~h}$ at $400 \mathrm{rpm}$ using a planetary ball mill. After drying, the mixture was milled again at $400 \mathrm{rpm}$ for $12 \mathrm{~h}$ and ground in a mortar. ${ }^{16}$ The mixtures were then calcined at $700{ }^{\circ} \mathrm{C}$ for $2 \mathrm{~h}$ in a tubular furnace under an Ar atmosphere. For comparison purposes, a reference material was made from the LCP precursor by calcination, hereafter referred to as pristine LCP.

The $\mathrm{VO}_{x}$ coating $(\mathrm{LCP} / \mathrm{V})$ was applied on previously carboncoated LCP particles to prevent their degradation. In fact, while LCP needs to be calcined at elevated temperatures in an inert atmosphere $\left(700^{\circ} \mathrm{C}\right.$ in $\left.\mathrm{Ar}\right), \mathrm{VO}_{x}$ crystallizes already at $350{ }^{\circ} \mathrm{C}$, but it requires an ambient or oxidative atmosphere. Thus, the interposition of a protecting layer was necessary to prevent LCP oxidation during the crystallization of the $\mathrm{VO}_{x}$ layer. Thus, the LCP precursor was first coated with carbon using sucrose as the carbon source (as shown later in this manuscript). Then, the $\mathrm{VO}_{x}$ coating was applied as described previously. ${ }^{17} \mathrm{~A}_{2} \mathrm{~V}_{5}$ hydrogel was synthesized by dispersing crystalline $\mathrm{V}_{2} \mathrm{O}_{5}$ (Pechiney) in an aqueous solution of $\mathrm{H}_{2} \mathrm{O}_{2}$ (weight ratio of
$\mathrm{V}_{2} \mathrm{O}_{5}: \mathrm{H}_{2} \mathrm{O}_{2}=1: 10$ ) by stirring for $10 \mathrm{~min}$ at $0{ }^{\circ} \mathrm{C}$. Carbon coated LCP was added (weight ratio of LCP : $\mathrm{V}_{2} \mathrm{O}_{5}=0.97: 0.03$ ) and afterwards the dispersion was mixed for $3 \mathrm{~h}$ at room temperature by magnetic stirring at $300 \mathrm{rpm}$. After drying and grinding, the powder mixtures were recalcined at $350{ }^{\circ} \mathrm{C}$ for $5 \mathrm{~h}$ in a box furnace. Upon this latter step the carbon layer vanished completely as confirmed by $\mathrm{C} / \mathrm{H} / \mathrm{N}$ analysis.

\section{Physico-chemical investigation of coated and uncoated $\mathrm{LiCoPO}_{4}$}

Powder X-ray diffraction patterns were recorded between 10 and $78^{\circ}(2 \theta)$ with a step size of $0.011278^{\circ}$ on a Bruker D8 Advance diffractometer with a $\mathrm{Cu}-\mathrm{K} \alpha$ source $(\lambda=0.154 \mathrm{~nm})$. Thermogravimetric analysis in nitrogen and oxygen atmospheres of LCP before and after calcination was performed with a Discovery TGA (TA-Instruments). The samples were heated up to $700{ }^{\circ} \mathrm{C}$ with a heating rate of $5{ }^{\circ} \mathrm{C} \mathrm{min}^{-1}$. Elemental analysis $(\mathrm{C} / \mathrm{H} / \mathrm{N}$ analysis) was performed on a Vario Micro cube. The materials as well as the electrodes were characterized by high resolution scanning electron microscopy (SEM, Zeiss LEO 1550).

Transmission electron microscopy (TEM) was performed on an aberration-corrected JEOL-JEM2100 Microscope operated at $200 \mathrm{kV}$. The ground powder was dispersed directly onto a holey carbon coated $\mathrm{Cu}$ TEM grid.

\section{Electrode making and cell assembly}

Composite electrodes were made of $85 \mathrm{wt} \%$ active material, 10 wt $\%$ conductive carbon (C-Nergy, Super C45, Imerys) and 5 wt\% binder (CMC, DOW Wolff Celulosics, Walocel CRT2000 PA12). The CMC binder was first dissolved in ultrapure water by magnetic stirring for $12 \mathrm{~h}$ at $300 \mathrm{rpm}$. Conductive carbon was added to the solution and dispersed by magnetic stirring for an additional $3 \mathrm{~h}$. The active material was added and further mixed by magnetic stirring for $2 \mathrm{~h}$, followed by high speed mixing at $5000 \mathrm{rpm}$ for $10 \mathrm{~min}$. All slurries were cast immediately onto aluminum current collectors using a laboratory doctor blade coater. ${ }^{8}$ Disc electrodes $\left(1.13 \mathrm{~cm}^{2}\right.$, active material mass loading: 1.3 to $2.0 \mathrm{mg} \mathrm{cm}^{-2}$ for pristine LCP and LCP/C1 (sucrose as the carbon precursor), LCP/C2 (sucrose as the carbon precursor), $\mathrm{LCP} / \mathrm{C} 4$ (Tween $80 ®$ as the carbon precursor) and $\mathrm{LCP} / \mathrm{V}\left(\mathrm{V}_{2} \mathrm{O}_{5}\right.$ as the coating precursor); $3.8 \mathrm{mg} \mathrm{cm}^{-2}$ for $\mathrm{LCP} / \mathrm{C} 3$ (polyacrylic acid as the carbon precursor)) were punched, pressed at 4 tons for $1 \mathrm{~min}$ and dried at $120{ }^{\circ} \mathrm{C}$ under vacuum for $12 \mathrm{~h}$.

Cells were assembled in a three-electrode configuration in an Ar filled dry-box (MBraun, $\mathrm{H}_{2} \mathrm{O}$ and $\mathrm{O}_{2}$ contents $<1 \mathrm{ppm}$ ) with lithium metal foil (Rockwood Lithium) as the counter and reference electrodes. A glass fiber felt (Whatman ${ }^{\circledR}, \mathrm{GF} / \mathrm{D}$ ) was used as the separator, which was soaked in an electrolyte solution of $1 \mathrm{M} \mathrm{LiPF}_{6}$ in $1: 1$ (wt) EC/DMC (UBE).

\section{Electrochemical testing of coated and uncoated $\mathrm{LiCoPO}_{4}$ electrodes}

The electrochemical performance of the active materials was evaluated by subjecting the corresponding electrodes to galvanostatic cycle tests within $5.0 \mathrm{~V}$ and $4.0 \mathrm{~V}$ cut-off limits using a Maccor series 4000 battery tester. The testing protocol 
involved five cycles at charge/discharge current rates of $\mathrm{C} / 10$ followed by 100 cycles at a 1C rate. Finally, a set of five cycles at $\mathrm{C} / 10$ was repeated to verify the capacity retention. A material nominal capacity of $167 \mathrm{~mA} \mathrm{~h} \mathrm{~g}^{-1}$ was used to calculate the current density at the various rates.

Electrochemical impedance spectroscopy (EIS) measurements (frequency range from $500 \mathrm{kHz}$ to $15 \mathrm{mHz}$, sinusoidal amplitude $10 \mathrm{mV}$ ) were performed on the cells after cycling (see the cycling test above) using an AMETEK® ModuLab XM.

\section{Results and discussion}

\section{Physico-chemical investigation of coated and uncoated $\mathrm{LiCoPO}_{4}$}

Fig. 1a shows the XRD patterns of pristine, carbon-coated and $\mathrm{VO}_{x}$-coated LCP. Rietveld refinement of all samples ( $R_{\mathrm{wp}}$ between 3.89 and 5.36) (Bruker, TOPAS 4.2) was performed. The lattice parameters of all the coated samples are in good agreement with those of pristine LCP. For LCP/C2, LCP/C3 and $\mathrm{LCP} / \mathrm{C} 4$ additional reflections of $\mathrm{Co}_{2} \mathrm{P}$ are visible between $2 \theta$ angles of 40 and $44^{\circ}$ (Fig. 1b).

$\mathrm{Co}_{2} \mathrm{P}$ usually appears as an impurity phase upon synthesis and/or further processing of $\mathrm{LiCoPO}_{4}$, e.g., calcination in the
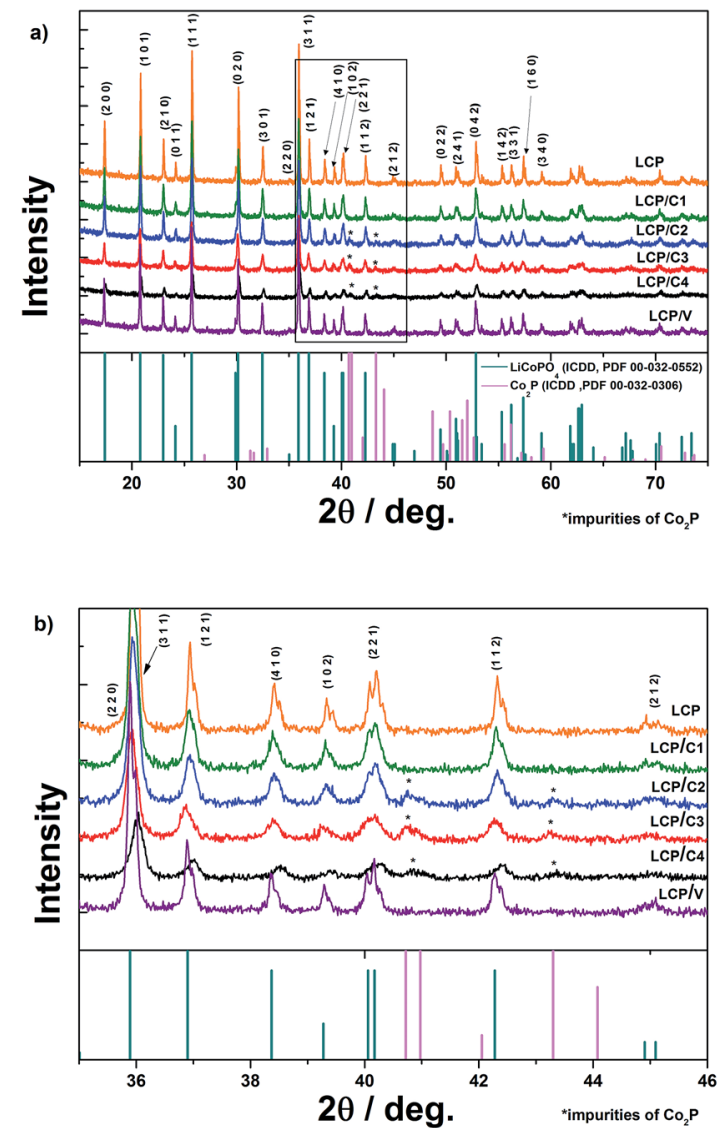

Fig. 1 (a) XRD patterns of pristine, carbon-coated and $\mathrm{VO}_{x}$-coated LCP materials and associated reference patterns of $\mathrm{LiCOPO}_{4}$ (ICDD, PDF 00-032-0552) and $\mathrm{CO}_{2} \mathrm{P}$ (ICDD, PDF 00-032-0306) and (b) in an expanded view between $2 \theta$ angles of 35 and 46 . presence of a carbon source in an inert atmosphere, due to the surface reduction of LCP. ${ }^{18,19} \mathrm{~A}$ dependence of the $\mathrm{Co}_{2} \mathrm{P}$ content using different coatings has been observed. In fact, LCP, LCP/C1 and LCP/V materials were almost phase pure, while LCP/C2, LCP/C 3 and LCP/C4 showed $\mathrm{Co}_{2} \mathrm{P}$ contents between 3 and $4 \%$ (see Table 1). However, it can be pointed out that even if a small but variable percentage of $\mathrm{Co}_{2} \mathrm{P}$ phase impurity was detected, the various coating processes had no major effect on the LCP crystal structure. ${ }^{20}$ Thermogravimetric analysis of the calcined pristine LCP, carbon-coated LCP materials (before and after calcination) and $\mathrm{VO}_{x}$-coated LCP (after calcination) was performed. The TGA curves of LCP materials coated with carbon precursors before calcination are compared with those of the pristine LCP precursor in Fig. 2a. While only a minor weight loss was observed for the pristine LCP precursor, the coated samples showed the weight loss typical of the coating carbonization along with the initial weight loss due to residual water. ${ }^{15,21}$ Under an inert atmosphere and in the presence of LCP, sucrose sharply decomposes at about $190{ }^{\circ} \mathrm{C}$, but the carbonization process is completed only at temperatures near $500{ }^{\circ} \mathrm{C}$. On the other hand, PAA and the oleic acid derivative (Tween 80 ) showed continuous decomposition (partially overlapping with the initial water release) ending at lower temperatures, but still higher than $400{ }^{\circ} \mathrm{C}$ (ESI Fig. S1†) ${ }^{\mathbf{1 5 , 2 1}}$

The characterization of the calcined uncoated and coated materials in an $\mathrm{O}_{2}$ atmosphere is presented in Fig. 2b. At higher temperatures, two different and contrasting phenomena take place, which are the weight loss due to the reaction of the carbon coating with oxygen and the weight increase due to the oxidation of the $\mathrm{Co}_{2} \mathrm{P}$ phase and/or the $\mathrm{VO}_{x}$ coating (around $400-500{ }^{\circ} \mathrm{C}$ ). These results are in very good agreement with the results obtained from XRD measurements. The materials showing higher amounts of $\mathrm{Co}_{2} \mathrm{P}$ impurity phase in the XRD pattern also show an increase in weight around 400 to $500{ }^{\circ} \mathrm{C}$ related to the reaction of the $\mathrm{Co}_{2} \mathrm{P}$ phase with oxygen. ${ }^{18,22}$ The weight increase observed for the $\mathrm{VO}_{x}$-coated LCP $(\mathrm{LCP} / \mathrm{V})$ is associated with the oxidation of vanadium, indicating that the latter is partially reduced during the crystallization process at $350{ }^{\circ} \mathrm{C} .{ }^{23}$

Since the overlapping of the carbon coating combustion with the $\mathrm{Co}_{2} \mathrm{P}$ oxidation did not make it possible to determine the carbon content of the various coatings by TGA, C/H/N analysis was performed. The results (see Table 1) showed that all carboncoated samples had a carbon content below 4 wt $\%$. For example, using $20 \mathrm{wt} \%$ of polyacrylic acid as the carbon source (C3) resulted in the highest carbon content (3.2 wt\%) while $20 \mathrm{wt} \%$ sucrose (C1) led to only $2.6 \mathrm{wt} \%$ of C. However, reducing the amount of sucrose to $10 \mathrm{wt} \%$ (C2) resulted in a non-linear decrease of carbon $(2.0 \mathrm{wt} \%)$. In spite of its large content (40 wt $\%$ with respect to the weight of LCP) Tween $80 \AA$ led only to $1.8 \mathrm{wt} \%$ of carbon coating. Finally, $\mathrm{C} / \mathrm{H} / \mathrm{N}$ analysis of sample $\mathrm{LCP} / \mathrm{V}$ demonstrated that the coating process of vanadium oxide led to the full removal of the preliminary carbon coating.

Fig. 3 shows the SEM images of coated and uncoated LCP samples, whose particle sizes were seen to vary between 50 and $300 \mathrm{~nm}$. Sucrose as the source for the carbon coating resulted in thin layers on the particle surface (Fig. 3a and b), samples 
Table 1 Carbon content of coated LCP materials (determined by $\mathrm{C} / \mathrm{H} / \mathrm{N}$ analysis) and lattice parameters and percentage of impurities of coated and uncoated LCP determined by Rietveld refinement (Bruker TOPAS 4.2) ${ }^{a}$

\begin{tabular}{|c|c|c|c|c|c|c|}
\hline Coating source & - & Sucrose & Sucrose & PAA & Tween $80 ®$ & $\mathrm{~V}_{2} \mathrm{O}_{5}$ \\
\hline Source vs. LCP in wt\% & - & 20 & 10 & 20 & 40 & 3 \\
\hline \multicolumn{7}{|l|}{$\mathrm{C} / \mathrm{H} / \mathrm{N}$ analysis } \\
\hline C-content in wt $\%$ & - & 2.6 & 2.0 & 3.2 & 1.8 & 0 \\
\hline$b(\AA)$ & $5.9231(2)$ & $5.9229(2)$ & $5.9242(2)$ & $5.9328(3)$ & $5.9313(3)$ & $5.9221(1)$ \\
\hline$c(\AA)$ & $4.7011(2)$ & $4.7006(2)$ & $4.7011(2)$ & $4.7043(3)$ & $4.7049(3)$ & $4.7004(1)$ \\
\hline Phase ratio of $\mathrm{Co}_{2} \mathrm{P}$ impurity in $\%$ & $0.3(2)$ & $0.4(2)$ & $2.6(2)$ & $3.4(2)$ & $4.1(2)$ & $0.2(2)$ \\
\hline$R_{\mathrm{wp}}$ & 4.80 & 5.36 & 3.89 & 4.25 & 4.46 & 4.96 \\
\hline
\end{tabular}

${ }^{a}$ Lattice parameters and phase ratios were determined using the program TOPAS 4-2 (see also, ESI Table S1).
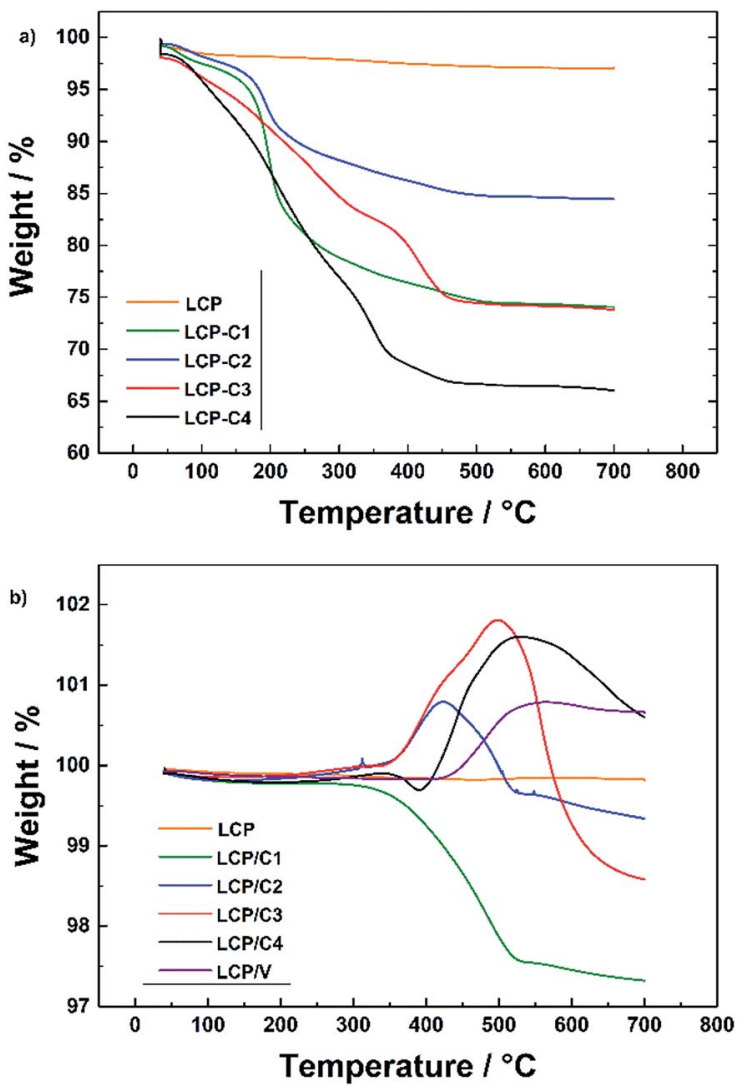

Fig. 2 (a) $\mathrm{TGA}$ in a $\mathrm{N}_{2}$ (heating rate of $5{ }^{\circ} \mathrm{C} \mathrm{min}^{-1}$ ) atmosphere of uncalcined LCP with different carbon sources and (b) TGA in an $\mathrm{O}_{2}$ atmosphere (heating rate of $5^{\circ} \mathrm{C} \mathrm{min}^{-1}$ ) of pristine, carbon-coated and $\mathrm{VO}_{x}$-coated LCP materials.

LCP/C1 and LCP/C2, while for both PAA (Fig. 3c, sample LCP/C3) and Tween $80 ®$ (Fig. 3d, sample LCP/C4) a thick film was visible, probably due to their incomplete degradation. For these latter samples an inhomogeneous distribution of particle aggregates was also observed. Regarding the $\mathrm{VO}_{x}$-coated material no film was observed in the SEM image (Fig. 3e, sample

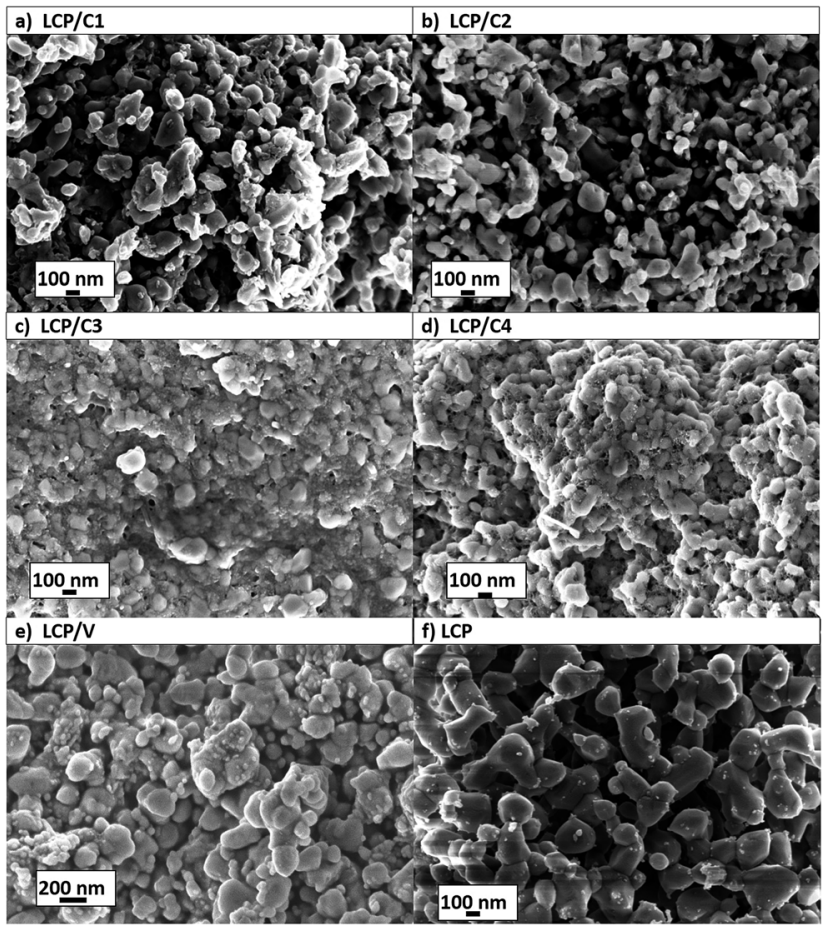

Fig. 3 SEM of pristine and coated LCP powders. (a) 20 wt\% sucrose, (b) $10 \mathrm{wt} \%$ sucrose, (c) $20 \mathrm{wt} \%$ polyacrylic acid, (d) $40 \mathrm{wt} \%$ Tween $80 \AA$, (e) $3 \mathrm{wt} \% \mathrm{~V}_{2} \mathrm{O}_{5}$, and (f) pristine LCP.

$\mathrm{LCP} / \mathrm{V}$ ), but small $\mathrm{VO}_{x}$ particles lying on the surface of the LCP particles were detected. Nevertheless, TEM investigations (Fig. 4e) showed the formation of a homogeneous, but rather thick $\mathrm{VO}_{x}$ surface layer (up to $8 \mathrm{~nm}$ thick) on the LCP particles. The same is true for LCP/C1, which showed (Fig. 4a) a homogeneous coating layer with a well-defined thickness of about 3 nm. LCP/C2 (Fig. 4b) showed a carbon layer on the entire surface; however, it is not homogeneous in thickness, whereas LCP/C3 and LCP/C4 (Fig. 4c and d, respectively) showed partially uncoated areas. These observations were confirmed by EDX line scan measurements (ESI Fig. S2 $\dagger$ ). Additionally, SEM 


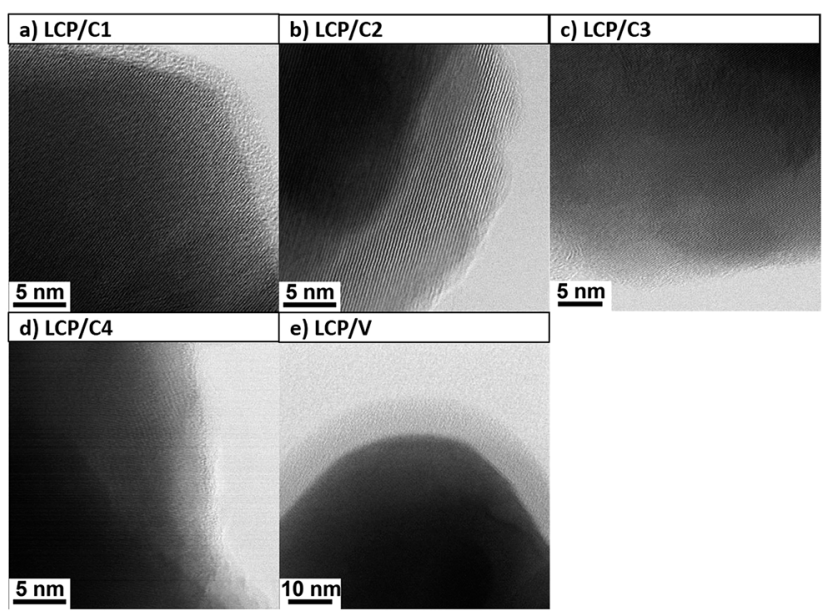

Fig. 4 TEM images of coated LCP particles. (a) 20 wt\% sucrose, (b) 10 wt $\%$ sucrose, (c) 20 wt \% polyacrylic acid, (d) 40 wt\% Tween $80 \circledast$, and (e) $3 \mathrm{wt} \% \mathrm{~V}_{2} \mathrm{O}_{5}$.

images of the electrode surface were taken, and are described briefly in the ESI (Fig. S3†).

\section{Electrochemical investigation of pristine and coated LCP electrodes}

The results of the long-term galvanostatic cycling of pristine and coated LCP electrodes are shown in Fig. $5 \mathrm{a}$ and b. Materials LCP/C3 and LCP/C4 were excluded from deeper electrochemical studies because of the incomplete coating leading to substantial capacity fading (see Fig. 4).

Upon charging all electrodes showed two plateaus during the first charge (Fig. 5c) associated with the two-step $\mathrm{Li}^{+}$-deinsertion mechanism, ${ }^{24,25}$ which is better evidenced by the two peaks appearing in the differential capacity plot (Fig. 5e). The first plateau, occurring between 4.80 and $4.86 \mathrm{~V}$, involves the extraction of about 0.3 eq. of $\mathrm{Li}^{+}$, while the second one (between 4.88 and $4.93 \mathrm{~V}$ ) is associated with the full delithiation of the active material, theoretically leading to $\mathrm{CoPO}_{4}{ }^{24,26,27}$ However, the charge specific capacities of LCP/C1 and LCP/C2 (both coatings using sucrose as the carbon source) are well above the theoretical value. Such an extraordinary capacity is certainly associated with electrolyte decomposition rather than the oxidation of the carbon coating because of the quite low amount of carbon in the coating (see Table 1). ${ }^{7}$ However, the carbon coating is certainly playing a role in increasing the electrode conductivity and the electrolyte/electrode contact area, thus even favoring the electrolyte decomposition. The $\mathrm{VO}_{x}$-coated material, on the other hand, showed a delithiation behavior similar to that of pristine LCP.

Upon the first discharge, however, electrodes of LCP/C1 and LCP/C2 performed better than the other two materials. This is in agreement not only with the higher delithiation level, but also with the very low amounts of phase impurities and complete surface coating of the LCP particles (see XRD and TEM results). During the first cycle (C/10 rate) LCP/C1 and LCP/C2 delivered discharge capacities of 120 and $100 \mathrm{~mA}$ $\mathrm{h} \mathrm{g}^{-1}$, respectively, whereas pristine LCP only achieved $90 \mathrm{~mA} \mathrm{~h} \mathrm{~g}{ }^{-1}$. Once more, the $\mathrm{VO}_{x}$-coated material showed similar performance to pristine LCP (slightly more than $80 \mathrm{~mA} \mathrm{~h} \mathrm{~g}^{-1}$ ).

Upon discharge, however, all electrodes showed much lower capacities than those observed during the first charge. As mentioned earlier, such an irreversible behavior is associated not only with the degradation of the electrolyte, but also with the nucleophilic attack of $\mathrm{F}^{-}$on phosphorus atoms destroying $\mathrm{P}-\mathrm{O}$ bonds and therefore, damaging the olivine structure. ${ }^{28}$ The carbon-coated materials (LCP/C1 and LCP/C2) displayed the highest first cycle irreversible capacity as a result of the massive electrolyte decomposition discussed above. However, in the following low rate $(\mathrm{C} / 10)$ cycles these two materials showed rapidly improving reversibility. As well the $\mathrm{VO}_{x}$-coated material showed faster improvement than pristine LCP.

With respect to the capacity retention of the active materials, pristine LCP showed, among all, the fastest capacity fading upon the initial low rate $(\mathrm{C} / 10)$ cycles, indicating that any of the coating had some beneficial effect on the capacity retention. Nevertheless, it is important to notice that the electrolyte decomposition occurring in the initial cycles for all electrodes may lead to the formation of a layer, usually called the Solid Electrolyte Interface (SEI), as observed for LCP and other high voltage electrodes. ${ }^{29-31}$

Upon long-term, high rate cycling (Fig. 5b) all materials show performance fading. In particular, the $\mathrm{VO}_{x}$-coated $(\mathrm{LCP} / \mathrm{V})$ and pristine LCP electrodes' specific capacities decreased to or even below $10 \mathrm{~mA} \mathrm{~h} \mathrm{~g}{ }^{-1}$ within a few cycles. On the other hand, LCP/C1 and LCP/C2 showed still appreciable delivered capacities (about $40 \mathrm{~mA} \mathrm{~h} \mathrm{~g}^{-1}$ ) after 100 cycles at 1C. This resulted from the better capacity retention of the LCP/C2 electrode. In fact, while LCP/C1 showed the highest initial capacity, both at $\mathrm{C} / 10$ and $1 \mathrm{C}, \mathrm{LCP} / \mathrm{C} 2$ showed better capacity retention $(62 \%$ for $\mathrm{LCP} / \mathrm{C} 1$ and $70 \%$ for LCP/C2 comparing the $5^{\text {th }}$ (Fig. S4 $\dagger$ ) and the $112^{\text {th }}$ cycle). After 100 cycles, LCP/C1 and LCP/C2 showed a very similar performance at a $\mathrm{C} / 10$ rate, showing also very similar differential capacity and voltage profiles. Overall, the uniform carbon coating obtained by using sucrose is certainly protecting the active material from reactions due to electrolyte decomposition.

In order to better understand the reason for the different performances of the materials upon cycling, electrochemical impedance spectroscopy measurements were performed on cycled cells. In particular, after the standard long-term cycling test, the cell was charged to $5 \mathrm{~V}$ and immediately discharged to $4.8 \mathrm{~V}$ and held for two hours at that potential prior to performing the EIS measurements. Fig. 6 shows the Nyquist plots of LCP, LCP/C1, LCP/C2 and LCP/V electrodes recorded at a constant potential of $4.8 \mathrm{~V}$. The LCP and LCP/C1 electrodes were subjected to a further discharge and charge cycle during which EIS measurements (Fig. 7) were taken at different voltages (after 2 hour potentiostatic equilibration).

The Nyquist plots in Fig. 6a all show a semicircle associated with the electrode/electrolyte interface, followed by an almost straight line associated with diffusion-limited processes occurring in the bulk of the electrodes. For all electrodes, the high to 

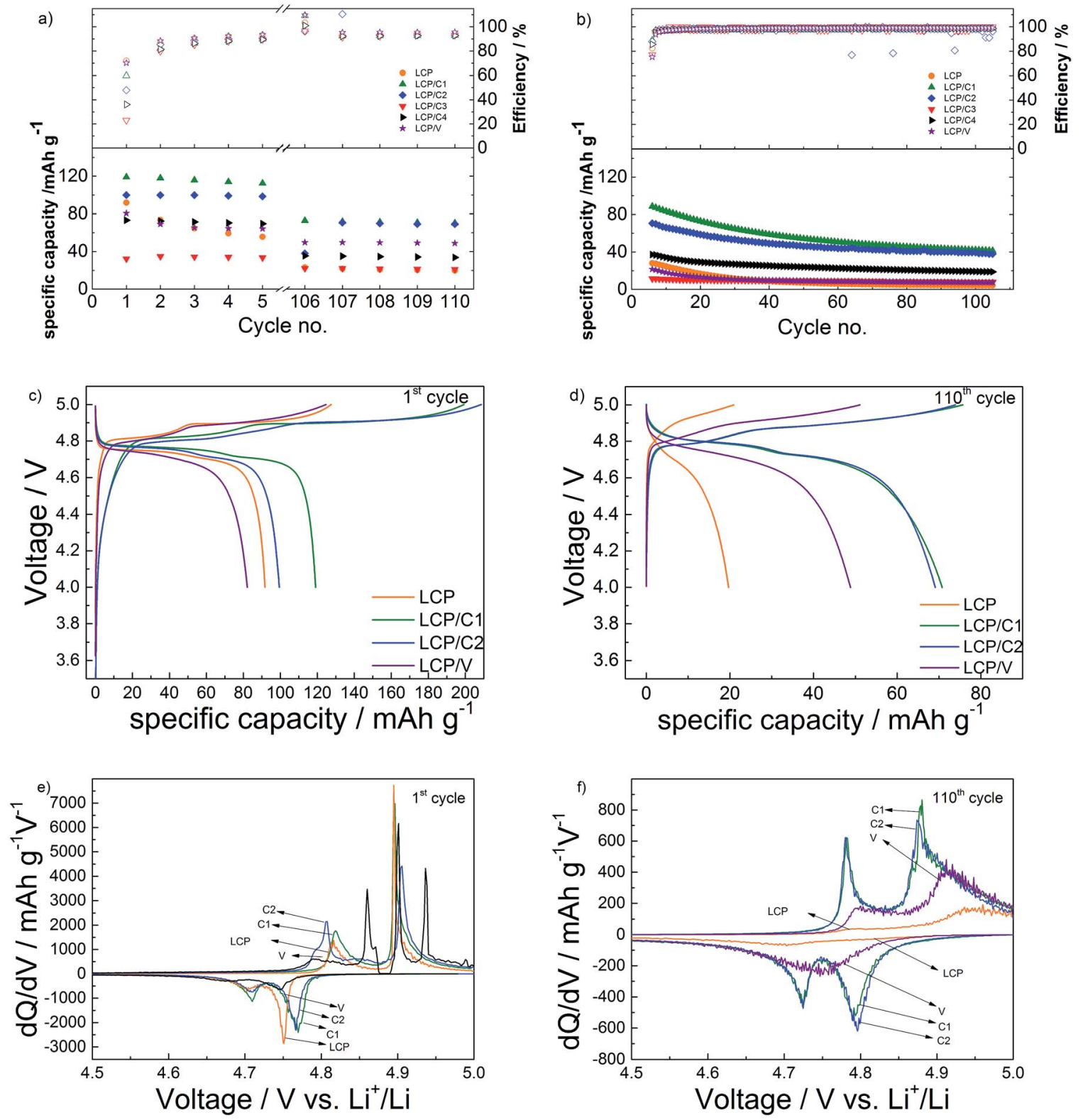

Fig. 5 Electrochemical performance of pristine and coated LCP electrodes. (a) Specific capacity vs. cycle number upon galvanostatic cycling at C/10 (cycles 1-5 and 106-110). (b) Specific capacity vs. cycle number upon galvanostatic cycling at $1 C$ (cycles $6-105)$. (c) $1^{\text {st }}$ and (d) $110^{\text {th }}$ cycles of selected materials; differential capacity plot of selected materials in the (e) $1^{\text {st }}$ and (f) $110^{\text {th }}$ cycles.

medium frequency semicircle appears to be strongly depressed, which is expected considering that it reflects both the charge transfer and the SEI impedance. In the case of the $\mathrm{VO}_{x}$-coated LCP electrode, however, two parallel (RC) elements were used to obtain the best fit (inset of Fig. 6b). ${ }^{32-34}$ The extent of the high frequency feature was strongly affected by the various coatings. In fact, electrodes $\mathrm{LCP} / \mathrm{C} 1$ and $\mathrm{LCP} / \mathrm{C} 2$ showed a rather moderate interface resistance, about $50 \%$ of the LCP resistance (see Table $\mathrm{S} 2 \dagger$ ). On the other hand, the $\mathrm{VO}_{x}$-coated sample showed a large interface resistance (see the expanded plot in Fig. $6 \mathrm{~b}$ and Table S2 $\uparrow)^{35,36}$ Interestingly, for LCP, LCP/C1 and LCP/C2 electrodes a loop at the end of the semicircle was still observed which is indicative of irreversible processing occurring during the measurements at different voltages. This was not the case for the $\mathrm{VO}_{x}$-coated electrode.

Comparing the impedance results of the carbon coated samples after galvanostatic cycling test confirms that LCP/C1 and LCP/C2 show the best performance (Fig. 5 and 7). The overall resistance is reduced significantly in comparison to pristine LCP for both samples. After 112 cycles, the impedance measurements do not show significant differences between $\mathrm{LCP} / \mathrm{C} 1$ and $\mathrm{LCP} / \mathrm{C} 2$, confirming the galvanostatic cycling results for these samples. In contrast for $\mathrm{LCP} / \mathrm{V}$ the overall resistance is significantly higher ( 420 to $490 \Omega$ ) underlining the assumption that the non-conductive coating layer, especially after being exposed to the electrolyte upon cycling, is too thick. 


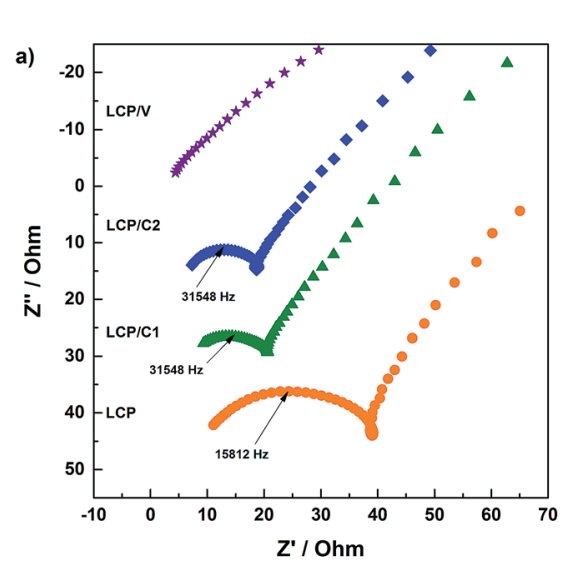

$112^{\text {th }}$ cycle

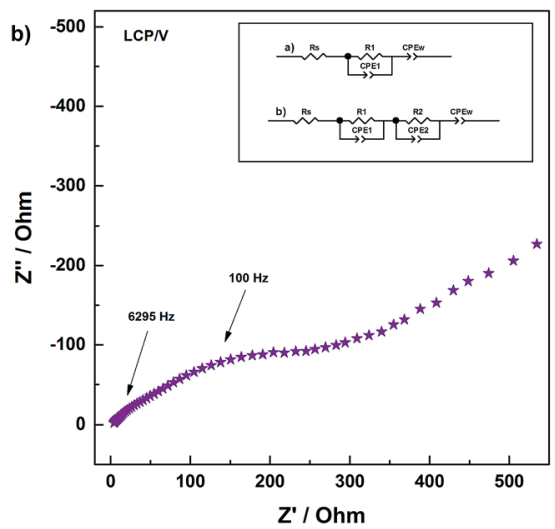

Fig. 6 Nyquist plots of pristine LCP, LCP/C1, LCP/C2 and LCP/V at 4.8 $\checkmark$ during discharge in the $112^{\text {th }}$ cycle showing the high and medium frequency regions. The Nyquist plot of LCP/V is shown also on a wider scale due to its higher impedance. The equivalent circuits used for the fitting of EIS measurements at $4.8 \mathrm{~V}$ of discharge are also illustrated.

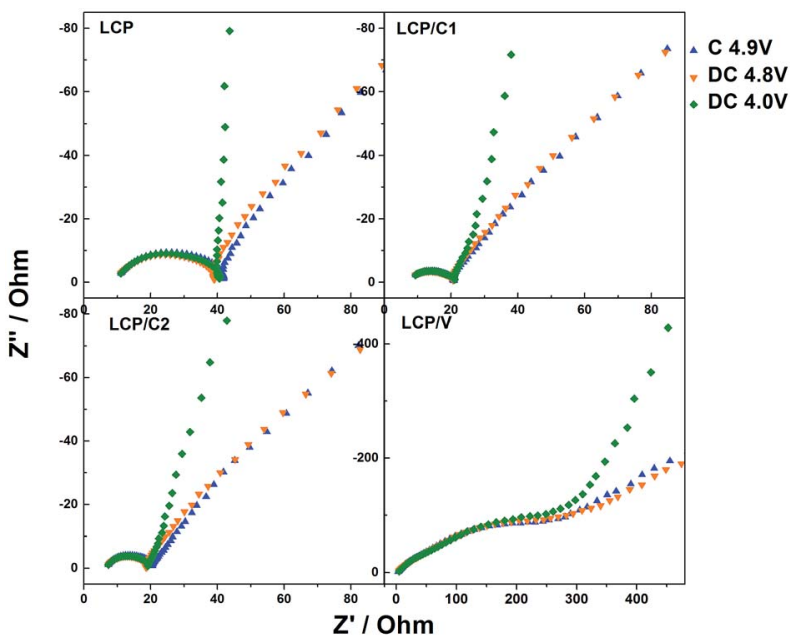

Fig. 7 Electrochemical impedance spectra (high and medium frequencies) of pristine LCP, LCP/C1, LCP/C2 and LCP/V at different states of charge (4.9 $\mathrm{V}$ charge, $4.8 \mathrm{~V}$ discharge and $4.0 \mathrm{~V}$ discharge) upon cycling (C/10 for 6 cycles, $1 C$ for 100 cycles, and C/10 for 6 cycles) during the $112^{\text {th }}$ cycle.

\section{Conclusions}

Different carbon and $\mathrm{VO}_{x}$ coatings were successfully applied to LCP while maintaining the phase purity of the active material.

All coated materials (together with pristine LCP) were processed into electrodes using, for the first time, an aqueous binder. The investigation on the coatings' effect on the electrodes' capacity and cycling stability, performed using a combination of analytical techniques including impedance spectroscopy, showed that the formation of a homogeneous carbon coating enhances both the first cycle capacity $(120 \mathrm{~mA} \mathrm{~h}$ $\mathrm{g}^{-1}$ ) and capacity retention upon cycling. Nevertheless, the typical fading of LCP-based materials, mainly due to the electrolyte decomposition at high operating voltages, is still present. After 112 cycles the carbon-coated LCP electrodes (LCP/ $\mathrm{C} 1$ and LCP/C2) offered a specific capacity of only $70 \mathrm{~mA} \mathrm{~h} \mathrm{~g}^{-1}$. Although the thicker carbon coating ( $20 \mathrm{wt} \%$ of sucrose as the precursor) showed a superior capacity during the first cycles, it also showed a more severe fading upon cycling. Coating the material with $\mathrm{VO}_{x}$, instead, leads to a significant capacity reduction, especially at $1 \mathrm{C}$ rate.

Nevertheless, the coating approach appears as a good strategy for increasing the LCP electrode capacity retention upon cycling.

\section{Acknowledgements}

The support from the European Commission under the MARSEV (Grant agreement no. 609201) project is gratefully acknowledged. Imerys and Rockwood Lithium are kindly acknowledged for supplying the C-NERGY Super C45 carbon additive and lithium foil, respectively. Furthermore, the authors would like to thank Dr Jan von Zamory for performing SEM analysis.

\section{References}

1 D. Aurbach, J. Power Sources, 2000, 89, 206-218.

2 B. Scrosati and J. Garche, J. Power Sources, 2010, 195, 24192430.

3 O. K. Park, Y. Cho, S. Lee, H.-C. Yoo, H.-K. Song and J. Cho, Energy Environ. Sci., 2011, 4, 1621-1633.

4 J. Li, S. Jeong, R. Kloepsch, M. Winter and S. Passerini, J. Power Sources, 2013, 239, 490-495.

5 C. M. Julien and A. Mauger, Ionics, 2013, 19, 951-988.

6 J.-M. Tarascon and M. Armand, Nature, 2001, 414, 359-367.

7 C. A. Michael Metzger, C. Marino, D. Haering, C. Kavakli and H. A. G. Sreeraj Puravankara, T. Nilges and C. Stinner, in 2014 ECS and SMEQ Joint International Meeting, 2014.

8 N. Loeffler, J. von Zamory, N. Laszczynski, I. Doberdo, G.-T. Kim and S. Passerini, J. Power Sources, 2014, 248, 915-922.

9 J. Li, C. Daniel and D. Wood, J. Power Sources, 2011, 196, 2452-2460.

10 G. Liu, H. Zheng, S. Kim, Y. Deng, A. M. Minor, X. Song and V. S. Battaglia, J. Electrochem. Soc., 2008, 155, A887-A892.

11 S. S. Jeong, N. Böckenfeld, A. Balducci, M. Winter and S. Passerini, J. Power Sources, 2012, 199, 331-335. 
12 S. F. Lux, F. Schappacher, A. Balducci, S. Passerini and M. Winter, J. Electrochem. Soc., 2010, 157, A320-A325.

13 L. Qiu, Z. Shao, D. Wang, W. Wang, F. Wang and J. Wang, Carbohydr. Polym., 2014, 111, 588-591.

14 F. Mueller, D. Bresser, E. Paillard, M. Winter and S. Passerini, J. Power Sources, 2013, 236, 87-94.

15 Y. Wang, I. Deen and I. Zhitomirsky, J. Colloid Interface Sci., 2011, 362, 367-374.

16 Y.-G. Huang, F.-H. Zheng, X.-H. Zhang, Q.-Y. Li and H.-Q. Wang, Electrochim. Acta, 2014, 130, 740-747.

17 N. Laszczynski, J. von Zamory, J. Kalhoff, N. Loeffler, V. S. K. Chakravadhanula and S. Passerini, ChemElectroChem, 2015, 2, 1768-1773.

18 J. Wolfenstine, J. Read and J. L. Allen, J. Power Sources, 2007, 163, 1070-1073.

19 X. Lin, Y. Zhao, Z. Liang, D. Yan, X. Liu, M. Wen, Y. Dong and Q. Kuang, J. Alloys Compd., 2015, 646, 727-733.

20 K. Amine, H. Yasuda and M. Yamachi, Electrochem. SolidState Lett., 2000, 3, 178-179.

21 H. Chen, B. Dou, Y. Song, Y. Xu, Y. Zhang, C. Wang, X. Zhang and C. Tan, Fuel, 2012, 95, 425-430.

22 J. Ni, H. Wang, L. Gao and L. Lu, Electrochim. Acta, 2012, 70, 349-354.

23 C. Piccirillo, R. Binions and I. P. Parkin, Chem. Vap. Deposition, 2007, 13, 145-151.

24 N. N. Bramnik, K. Nikolowski, C. Baehtz, K. G. Bramnik and H. Ehrenberg, Chem. Mater., 2007, 19, 908-915.
25 S. Theil, M. Fleischhammer, P. Axmann and M. WohlfahrtMehrens, J. Power Sources, 2013, 222, 72-78.

26 N. N. Bramnik, K. G. Bramnik, T. Buhrmester, C. Baehtz, H. Ehrenberg and H. Fuess, J. Solid State Electrochem., 2004, 8, 558-564.

27 M. Nakayama, S. Goto, Y. Uchimoto, M. Wakihara and Y. Kitajima, Chem. Mater., 2004, 16, 3399-3401.

28 E. Markevich, R. Sharabi, H. Gottlieb, V. Borgel, K. Fridman, G. Salitra, D. Aurbach, G. Semrau, M. A. Schmidt, N. Schall and C. Bruenig, Electrochem. Commun., 2012, 15, 22-25.

29 J. Xu, S.-L. Chou, M. Avdeev, M. Sale, H.-K. Liu and S.-X. Dou, Electrochim. Acta, 2013, 88, 865-870.

$30 \mathrm{M} . \mathrm{Xu}, \mathrm{N}$. Tsiouvaras, A. Garsuch, H. A. Gasteiger and B. L. Lucht, J. Phys. Chem. C, 2014, 118, 7363-7368.

31 L. Yang, B. Ravdel and B. L. Lucht, Electrochem. Solid-State Lett., 2010, 13, A95-A97.

32 B. Jin, H.-B. Gu and K.-W. Kim, J. Solid State Electrochem., 2008, 12, 105-111.

33 J. L. Allen, T. Thompson, J. Sakamoto, C. R. Becker, T. R. Jow and J. Wolfenstine, J. Power Sources, 2014, 254, 204-208.

34 J. P. Schmidt, T. Chrobak, M. Ender, J. Illig, D. Klotz and E. Ivers-Tiffée, J. Power Sources, 2011, 196, 5342-5348.

35 S.-L. Chou, J.-Z. Wang, J.-Z. Sun, D. Wexler, M. Forsyth, H.-K. Liu, D. R. MacFarlane and S.-X. Dou, Chem. Mater., 2008, 20, 7044-7051.

36 C. Leger, S. Bach, P. Soudan and J.-P. Pereira-Ramos, J. Electrochem. Soc., 2005, 152, A236-A241. 